\title{
ENTRE A LINGUAGEM E O SABER-FAZER: UMA PROPOSTA PARA A COMPREENSÃO DO CONHECIMENTO PRÁTICO
}

\author{
Marina Dantas de Figueiredo \\ Universidade de Fortaleza (Unifor), Fortaleza, Ceará, Brasil
}

\begin{abstract}
REsUMO: O artigo tem como objetivo formular alternativas para transpor as dificuldades em pesquisar o fenômeno da aprendizagem na prática, entendido como saber-fazer. Para isso, constroem-se articulações teóricas que colocam em paralelo uma perspectiva fenomenológica, baseada no paradigma da corporeidade, e uma abordagem que reúne linguagem e prática, qual seja a teoria das metáforas incorporadas. Entende-se que tais dificuldades estão orientadas em torno de pressupostos ontológicos da ciência moderna, quais sejam: os limites entre objetividade e subjetividade e as formas de representação e comunicação do conhecimento. Conclui-se que a pesquisa etnográfica desenvolvida segundo modelos fenomenológicos, tais como as categorias da etnografia da experiência, seja uma proposta metodológica adequada para o estudo do conhecimento prático.

Palavras-chave: Conhecimento prático. Paradigma da Corporeidade. Saber-fazer. Etnografia.
\end{abstract}

INTRODUÇÃO

Embora a ênfase nas práticas tenha possibilitado reflexões sobre os processos de incorporação do conhecimento, o fenômeno da aprendizagem é tradicionalmente abordado a partir de um viés cognitivista. Ainda são 
poucos os estudos que ultrapassam as fronteiras das dualidades entre corpo/ mente e sujeito/objeto, para situar os processos de aprendizagem na prática em um lugar ontológico onde cognição e cultura possam se encontrar. Isso se deve, em grande medida, às dificuldades de compreender e transmitir as especificidades do conhecimento prático (o saber-fazer) no âmbito das pesquisas acadêmicas que, mormente, obedecem a critérios positivistas de comunicação científica. $O$ conhecimento prático é alheio e até mesmo reativo a representações, uma vez que pertence ao domínio daquilo que os sujeitos sabem com o corpo e aprendem durante a performance prática. Apesar disso, dadas as formas correntes de produção científica, o conhecimento prático, quando pesquisado, ainda precisa ser compreendido e analisado por meio de artifícios representacionais que não capturam o sentido da experiência do saber-fazer, mas que são os recursos disponíveis para a comunicação intersubjetiva.

Acreditamos que articulações teóricas que se proponham a alinhar, sob o paradigma da corporeidade (COSRDAS, 1990), a perspectiva fenomenológica (MERLEAU-PONTY, 2005 [1945]) e as teorias da Linguísticas sobre metáforas incorporadas (LAKOFF; JOHNSON, 1980; 1999), possam contribuir para o avanço dos estudos a respeito do conhecimento prático. Neste artigo, buscamos entender como a linguagem pode ser recurso suficiente para captar a experiência da aprendizagem na prática que caracteriza o saber-fazer. Nosso objetivo é lançar bases teóricas para novas propostas metodológicas em pesquisas que tomem o conhecimento prático como objeto empírico. Por meio desse esforço, esperamos subsidiar uma aproximação coerente entre práticas e representações, por meio de uma forma específica de entendimento da relação entre experiência vivencial e linguagem.

A existência entrelaçada do corpo e do mundo sócio-cultural é um entendimento fundamental para as formulações que desenvolveremos neste artigo. A questão foi abordada de maneiras diferentes pelas teorias que tomaremos como referências. Os autores com os quais trabalharemos dedicaram esforços à compreensão da situação do corpo no mundo e nos deteremos mais especificamente no modo como eles lidaram com o corpo que aprende no contato com o mundo e qual a importância da linguagem 
nesse processo. Da perspectiva fenomenológica de Merleau-Ponty (2005) decorrem entendimentos diferentes sobre os processos cognitivos originados no corpo, que se aproximam na reflexão de Csordas (1990) sobre a Antropologia Cognitiva. Assim, abrimos espaço para uma explicação da linguagem enquanto fenômeno incorporado, que será tratada por Lakoff e Johnson (1980; 1999) e permitirá generalizações para a associação entre a linguagem e as experiências vivenciais.

Os três suportes conceituais escolhidos apresentam continuidades e estão no topos ontológico da dissolução de fronteiras entre natureza e cultura. Os autores que selecionamos são fundamentais para o desenvolvimento da argumentação teórica e também para delinear métodos para a coleta, a análise e apresentação de dados em pesquisas sobre conhecimento prático, visto que desconstroem a dualidade entre indivíduo e ambiente e recusam a visão mecanicista que coloca o cérebro no centro dos processos cognitivos. Por meio das propostas que tomamos como ponto de partida para o estudo do corpo que aprende, procuramos reconhecer a importância do engajamento ativo do indivíduo no ambiente e (re)situar a cultura num espaço intersticial entre esses dois domínios interdependentes.

Sendo assim, será fundamental para os nossos propósitos compreender como cada um desses conceitos de corpo e corporeidade se relaciona com a cultura e o paradigma da corporeidade (embodiment), possibilitando explicações incorporadas dos fenômenos da cognição e da linguagem. Procuraremos, portanto, explorar como esses conceitos que tratamos como principais descrevem os processos de aquisição e manejo da linguagem no contexto das experiências do corpo e das trocas fecundas com o ambiente. Assim, buscaremos assimilar uma concepção de corpo e corporeidade que se relacione com a linguagem enquanto processo cognitivo incorporado, para além dos limites das representações que perpetuam a dualidade entre corpo e mente.

\section{CoRPoreidade E Linguagem}

O paradigma da corporeidade se apresenta como uma mudança de perspectiva nas Ciências Sociais e reflete sua aproximação com as Ciências 
da Natureza (VELHO, 2001). Nos primeiros esforços para o desenvolvimento das Ciências Cognitivas, a cultura desempenhava um papel periférico. $O$ conhecimento cultural era entendido como algo que residia na mente dos indivíduos e que poderia ser transmitido de um contexto cultural a outro, por meio de representações e traduções. As teorias cognitivistas, fortemente baseadas no mentalismo, pressupunham que os referentes empíricos da realidade eram o fundamento para o conhecimento objetivo. Trabalhando no interior da divisão cartesiana entre mente e mundo, sujeito e objeto, os cognitivistas de então propuseram que o conhecimento era um processo de aquisição de imagens mentais, palavras e significados que poderiam definir as coisas para os sujeitos. Entre a Psicologia e a Antropologia, havia uma implícita "distribuição intelectual de trabalho" que direcionava os esforços dos psicólogos para os 'processos cognitivos', ao passo que os antropólogos deveriam se preocupar com os "conteúdos cognitivos" (HUTCHINS, 1995, p. 353). Em meio a esse confronto de paradigmas, a Educação se filiou às duas posturas, elaborando abordagens psicológicas ou antropológicas para entender a questão do conhecimento e seus modos de transmissão pela via da linguagem e de outros modos de representação.

Na esteira da Fenomenologia Existencial de Merleau-Ponty (2005), Csordas (1990) argumenta em favor da experiência corporal como ponto de partida para a análise cultural, que encontra no nível pré-objetivo as bases existenciais para as elaborações interpretativas e verbais da vivência humana no mundo (CARVALHO; STEIL, 2008). O próprio Merleau-Ponty (2005) dedica um capítulo da obra basilar Fenomenologia da Percepção ao corpo como expressão através da fala, contrariando as visões da Psicologia Cognitivista e da Linguística sobre as palavras como representações do pensamento; ou seja, como significados culturalmente elaborados para dar forma ao pensamento que seria amorfo. Merleau-Ponty (2005) e Csordas (1990) se referirem à linguagem como expressão do corpo no mundo e como a possibilidade aberta de um exercício de alteridade no qual o significado das palavras, que têm uma espessura histórica e exprimem vivências de outrem, pode ser atualizado diante das experiências do próprio sujeito. 
A despeito da visão da Psicologia Intelectualista e da Linguística, que concebem as palavras como "imagens mentais" capazes de expressar o pensamento, Merleau-Ponty "recorrerá ao gesto para esclarecer a comunicação pela palavra, buscando no corpo não só a compreensão do problema da linguagem, mas também o entendimento de uma questão mais abrangente, a expressão" (FURLAN; BOCCHI, 2008, p. 448). Ele propõe que a fala autêntica é a manifestação das possibilidades comunicativas do corpo. Isso porque o ato de falar não é simplesmente um meio de expressão que traduz o pensamento amorfo nos termos de um padrão que lhe seria associado, mas se apresenta como uma verdadeira comunicação na qual o expresso não existe separado da expressão e onde os próprios signos induzem o sentido da experiência do mundo. Em outras palavras, o pensamento, no sujeito falante, não é uma representação, mas é a própria expressão da subjetividade. Por isso, “o orador não pensa antes de falar, nem mesmo enquanto fala; sua fala é seu pensamento" (MERLEAU-PONTY, 2005, p. 245). Relacionando diretamente fala e corporeidade, Merleau-Ponty (2005, p. 246) afirma que

Não preciso representar-me a palavra para sabê-la e para pronunciá-la. Basta que eu possua sua essência articular e sonora como uma das modulações, um dos usos possíveis de meu corpo (...) A palavra é um certo lugar no meu mundo linguístico, ela faz parte do meu equipamento, só tenho um meio de representá-la para mim; é pronunciá-la, assim como o artista só tem um meio de representar-se na obra na qual trabalha: é preciso que ele a faça.

Para Merleau-Ponty (2005, p. 239), ainda que exista um sentido por trás da palavra, ela não é sua possuidora; "é o pensamento que tem um sentido" e a palavra não é muito mais que um invólucro vazio. Ela é apenas um som, um fenômeno articular ou a consciência desse fenômeno, e serve como um veículo para a exteriorização do pensamento. É o sentido que habita a palavra, justamente porque a linguagem não nasce de processos intelectuais, mas sim da consciência do corpo a respeito de si mesmo e do espaço que o circunda. Desse modo, temos que

Se a fala pressupusesse o pensamento, se falar fosse em primeiro lugar unir-se ao objeto por uma intenção de conhecimento ou por uma representação, não se compreenderia por que o pensamento tende para a expressão como para o seu acabamento, por que o objeto mais familiar 
parece-nos indeterminado quando não encontramos o seu nome, porque o próprio sujeito pensante está em um tipo de ignorância de seus pensamento enquanto não os formulou para si ou mesmo disse e escreveu (MERLEAU-PONTY, 2005 p. 241).

A passagem a qual acabamos de nos referir explica como o gesto fonético realiza, para aquele que fala e para aqueles que o escutam, certa estrutura da experiência ou uma modulação da existência que permitem que o corpo invista sobre os objetos que o circulam uma dada significação (MERLEAU-PONTY, 2005). A força das palavras está contida nas possibilidades de ultrapassar e transfigurar as capacidades expressivas do corpo, ao transformarem uma série de atos descontínuos - como apertar a língua contra os dentes, aumentar a abertura da boca e soprar o ar - em núcleos significativos que comunicam a experiência entre subjetividades. "Esse ato de transcendência", afirma Merleau-Ponty (2005, p. 262), "encontra-se primeiramente na aquisição de um comportamento, depois na comunicação muda do gesto", quando "o corpo se abre a uma conduta nova e faz com que testemunhos exteriores a compreendam".

Ao postular a distinção entre fala falante e fala falada, Merleau-Ponty (2005) remete primeiro à linguagem em estado nascente e criativo e, depois, à linguagem sedimentada, constituída pelas significações correntes em um dado meio sócio-cultural (FURLAN; BOCCHI, 2008). A cultura é o cenário para que a memória de palavras e fonemas impressos no corpo retome uma experiência acabada a partir do momento presente, onde o passado pode encontrar significações novas. Cada sujeito imprime significados às palavras nas suas expressões particulares e, sendo assim, a comunicação se torna possível porque os sujeitos em relação conseguem tomar para si os gestos e intenções legíveis na conduta do outro. As atualizações constantes do presente acontecem quando as intenções comunicativas de um sujeito passam a habitar o corpo do outro, de modo que as condutas de um encontrem no outro a legitimação do sentido (FURLAN; BOCCHI, 2008). O corpo, então, é o meio permanente para que nós possamos nos posicionar no tempo e fabricar "pseudo-presentes" que nos permitam a comunicação com o mundo (MERLEAU-PONTY, 2005). 
Merleau-Ponty foi um crítico das teorias da linguagem de seu tempo quando recusou a exterioridade entre significante e significado e a cisão entre pensamento e fala. Ao nomear o corpo enquanto sede da comunicação e elevar a linguagem à expressão plena da subjetividade, ele atribui ao gesto o papel central no trabalho de compreensão dos sentidos das palavras."Toda a dificuldade", adverte, "é conceber bem esse ato e não confundi-lo com uma operação de conhecimento" (MERLEAU-PONTY, 2005, p. 251). O gesto, que atualiza o passado comum da cultura no momento presente, se coloca diante dos sujeitos como uma questão e indica certos pontos sensíveis do mundo por onde os corpos podem adentrar para experimentar o significado das palavras no contexto da comunicação. Segundo a explicação de Merleau-Ponty (2005), é pelo corpo que compreendemos o outro, da mesma forma que é pelo corpo que percebemos as coisas. "Assim 'compreendido'", complementa, "o sentido do gesto não está atrás dele, ele se confunde com a estrutura do mundo que o gesto desenha e que por minha conta eu retomo; ele se expõe no próprio gesto" (MERLEAU-PONTY, 2005, p. 253).

Merleau-Ponty (2005) nos ensina que a comunicação por meio da linguagem é a própria expressão do corpo, que precisa se tornar o pensamento ou a intenção que significa. Há, portanto, um sentido imanente ou nascente no corpo vivo que se manifesta através de símbolos e é igualmente capaz de apreender o sentido latente nos outros corpos no mundo. Quer se trate do próprio corpo ou do corpo do outro, não é possível conhecer o corpo humano e o mundo senão por meio do viver, o que retoma uma comunicação existencial na qual o corpo se confunde com o mundo. Portanto, acrescenta Merleau-Ponty (2005, p. 269), "sou meu corpo, exatamente na medida em que tenho um saber adquirido e, reciprocamente, meu corpo é um sujeito natural, como o esboço provisório do meu ser total". Assim, o corpo não é apenas um objeto entre os outros, ligado ao sujeito pela consciência de existir, mas é fonte de subjetividade em todos os seus pontos.

Agora que esclarecemos alguns entendimentos sobre a Fenomenologia de Merleau-Ponty (2005), especialmente no que diz respeito à linguagem como expressão legítima da subjetividade, temos subsídios para avançar em direção ao paradigma da corporeidade. Nele, Csordas (1990) propõe que a 
corporeidade, mais do que um conceito, é uma perspectiva paradigmática para o estudo da cultura e do self. Para o antropólogo, a corporeidade se inicia com o postulado metodológico de que "o corpo não é um objeto a ser estudado em relação à cultura, mas deve ser considerado um sujeito da cultura ou, em outras palavras, um plano existencial para a cultura" (CSORDAS, 1990, p. 5). Todavia, seu argumento se completa na conjugação de um interesse empírico diferente, segundo o qual, as estruturas sociais são incorporadas"na conjunção entre as condições objetivas de vida e a totalidade das aspirações e das práticas compatíveis com essas condições" (CSORDAS, 1990, p. 11). Seu plano para delinear o paradigma da corporeidade se vale, então, da Teoria da Percepção, no intuito de superar a dualidade entre sujeito e objeto, e da Teoria da Prática, para questionar a dualidade entre estrutura e prática. A exposição hermenêutica dessas duas orientações metodológicas resulta numa nova interpretação para a distinção sujeito-objeto, que delineia a questão metodológica central para o paradigma da corporeidade.

No que tange à linguagem, Csordas é, em grande medida, um continuador do pensamento de Merleau-Ponty (2005) e, assim como ele, defende que (1) a linguagem é a própria expressão da corporeidade e não desempenha um papel meramente representativo do pensamento; e (2) a cultura não se define apenas em termos de símbolos e significações, mas também nos termos das ações humanas que caracterizam o habitar o mundo (COSRDAS, 1990). Sua concepção de self baseado na corporeidade ocorre em um momento fenomenológico anterior à distinção entre corpo e mente, quando a linguagem serve ao processo cultural de autopercepção. Evitando as pressuposições de que os fenômenos da percepção são subjetivos e os fenômenos da prática são objetivos, Csordas (1990, p. 34) questiona "como, afinal, se chegam às objetificações culturais e objetificações do self'.

O paradigma da corporeidade requer a análise da distinção entre sujeito e objeto, bem como das distinções entre corpo e mente, si mesmo (self) e outro, entre cognição e emoção e entre subjetividade e objetividade nas Ciências Sociais, especialmente na Antropologia Psicológica. Csordas (1990, p. 36) diz que "se partirmos do mundo vivo dos fenômenos da percepção, nossos corpos não são objetos para nós"e, pelo contrário, "eles são uma parte 
integral do sujeito que percebe". Ele se detém na proposta cognitivista de Piaget (1967), segundo a qual, "o progresso da inteligência sensório-motora leva à construção de um universo objetivo em que o próprio corpo do sujeito é um elemento entre outros, e com o qual a vida interna, localizada no próprio corpo do sujeito, é contrastada", para refletir sobre questão objetividade-subjetividade numa perspectiva fenomenológica.

De acordo com Csordas (1990), a falha da Psicologia Cognitivista não repousa na manutenção dos limites entre objetividade e subjetividade que a Fenomenologia desfaz, mas no pressuposto de que essa divisão estrutura a mente que se separa do corpo. Ele afirma que Merleau-Ponty não negaria que construímos um universo objetivo nem que o desenvolvimento da capacidade de objetivar é fundamental para a nossa constituição, mas que o adulto totalmente desenvolvido que se movimenta no mundo trata o seu corpo como um objeto. Contrapondo a assertiva de Merleau-Ponty de que o corpo se define na relação com o mundo à proposta de Piaget, de que o corpo é um elemento entre outros num universo objetivo, Csordas (1990) põe em questão o problema da experiência enquanto expressão da subjetividade, conforme proposto pela Fenomenologia, em oposição à dualidade mente-corpo, subjetividade-objetividade, com a qual a Antropologia Psicológica opera. Baseado nisso, elabora a seguinte síntese: "quando os dois polos da dualidade são reformulados em termos vivenciais, o lema da Antropologia Psicológica de que toda realidade é psicológica já não tem uma conotação mentalista, mas define a cultura como corporificada desde o início" (CSORDAS, 1990, p. 37).

A força de sua ideia reside na afirmação bastante simples de que, se nós não percebemos nossos próprios corpos como objetos, também não podemos perceber outros corpos como objetos (CSORDAS, 1990). Se a Fenomenologia de Merleau-Ponty (2005) explica que a comunicação se realiza na experiência perceptiva incorporada, então somos levados a experimentar a subjetividade do outro numa dimensão intersubjetiva. Assim, o corpo das outras pessoas pode se tornar um objeto para nós apenas secundariamente, como resultado da reflexão. "A experiência de ser um outro self', diz Csordas (1990, p. 37), "é uma parte importante daquilo que distingue a nossa experiên- 
cia do outro social", que "está, em um sentido radical, na negação do próprio self (not-self)". O que há de ser levado em conta é que os objetos culturais, dentre os quais está o self, são constituídos e objetificados não durante o processo de socialização infantil, mas no fluxo de toda a vida cultural do adulto.

Csordas (1990) propõe que o paradigma da corporeidade deve permitir uma explicação corporificada da linguagem e analisa o problema da glossolalia - espécie de transe religioso, investigado pelo autor, no qual praticantes de cultos pentecostais falam línguas inventadas - como um fenômeno cultural e expressivo. "A glossolalia pentecostal é uma forma de expressão ritual caracterizada pela falta de um componente semântico", onde "todas as sílabas são 'sílabas sem sentido"' e os indivíduos desenvolvem "padrões fonológico-sintáticos" pronunciados como "linguagens de oração" (CSORDAS, 1990, p. 23). Do ponto de vista semiótico, a glossolalia rompe com o mundo de significados humanos e força a abertura do discurso para mudanças criativas. Do ponto de vista fenomenológico, no qual a linguagem é um gesto que expressa a existência dos sujeitos no mundo, o despojamento da dimensão semântica na glossolalia não é uma ausência, mas sim um ato corporal que nos remete aos fundamentos da linguagem natural sem, contudo, nos fazer ignorar que "uma vez que o silêncio inicial tenha sido abalado por um ato de expressão, o mundo linguístico e cultural é constituído" (COSRDAS, 1990, p. 27). Temos então que

Do ponto de vista da corporeidade, a glossolalia afirma a unidade entre corpo e mente, cria um mundo humano compartilhado e manifesta a transcendência - como fazem todas as línguas. O pensamento não é dependente do enunciado, o mundo humano é formado por uma mistura de vozes encarnadas e cada enunciado é um enunciado inicial, uma transcendência inicial. No entanto, a glossolalia faz isso de uma forma radical, já que o significado gestual da linguagem predomina (CSORDAS, 1990, p. 31).

Desse ritual, Csordas (1990) conclui que o corpo é o lócus do sagrado para os religiosos praticantes porque o corpo é a base existencial da cultura. Por meio do exemplo empírico, ele confirma o escopo paradigmático da corporeidade como uma forma de propor novas questões para os problemas da experiência e da percepção, além daquelas normalmente feitas pela Antropologia Psicológica, já que a relação corpo-mundo revela o quão 
implicada uma parte está na outra. O caráter dessa relação possibilita que outras dualidades que estão na base do pensamento antropológico (como sujeito-objeto, corpo-mente, self-outro, cognição-emoção, natureza-cultura) sejam superadas.

\section{As Metáforas Incorporadas PARA LaKOFF E JoHnSON}

A teoria das metáforas incorporadas de Lakoffe Johnson (1980; 1999) é produto da associação entre teorias linguísticas e teorias cognitivas e nos oferece meios para compreender como a linguagem pode ser tomada enquanto forma de comunicação intersubjetiva, por meio da qual o significado dos símbolos (das palavras) é elaborado no plano da ação. Assim, constrói-se um significado incorporado para as palavras, de modo que sua pronúncia (ou grafia) pode ser tomada como expressão da experiência de um sujeito, e a recepção da mesma por um ouvinte (ou leitor) deflagra nele as memórias da experiência na qual o significado daquela palavra se ampara.

No campo da linguagem, a metáfora pressupõe a comparação entre dois termos de naturezas diferentes, mas que guardam relação de similaridade entre o sentido próprio inerente a um, e o sentido figurado conferido a outro. De acordo com as teorias linguísticas clássicas, a metáfora é uma questão de linguagem e não de pensamento. Todavia, a partir da década de 1970, linguistas influenciados pelas teorias cognitivistas passaram a tentar entender como a linguagem metafórica condiciona certas formas de perceber e conceituar. Essas formulações foram aprofundadas quando novas técnicas para a análise da atividade cerebral, no âmbito da Neuropsicologia, permitiram, pela primeira vez, que a correlação entre cognição e ação fosse posta à prova. Conforme Varela (1996), muitos experimentos de então foram particularmente importantes para ajudar a responder à questão: "o que os relatos verbais expressam?" (VARELA, 1996, p. 339).

O conceito contemporâneo de metáfora tem origem no trabalho pioneiro de Reddy (1979) The conduit of metaphore. Ele demonstra, por meio de um número significativo de exemplos, que o lócus da metáfora é a cognição, e não a linguagem, e que este tipo de pensamento fundamenta o modo como conceituamos o mundo. Reddy (1979) parte da etimologia da 
palavra metáfora - transporte ou transferência de significado, de acordo com a origem grega - para explicar como nossos comportamentos cotidianos têm origem em um sistema de pensamento e linguagem baseado em experiências metafóricas. Ao propor que"o mundo não é um texto, mas sim os conceitos e emoções conjugados na leitura de um texto", Reddy (1979, p. 300) aponta o papel indispensável das metáforas para moldar nossa experiência do mundo.

A conclusão de que as metáforas são um sistema conceitual que estrutura pensamentos e condiciona ações abalou definitivamente a distinção entre linguagem literal e linguagem figurada. Com o lançamento do livro Metaphores we live by, em 1980, o linguista George Lakoff e o filósofo Mark Johnson evidenciam a importância das metáforas enquanto mecanismo cognitivo, capaz de relacionar nossas experiências físicas e sociais, e moldar nossa maneira de perceber o mundo. Em Philosophy in the flesh (1999), eles retomam as ideias propostas no trabalho anterior e descrevem as correspondências entre os diferentes domínios que se equivalem na metáfora por meio de mapas conceituais baseados nas experiências do corpo.

Para propor a teoria das metáforas incorporadas, Lakoff e Johnson $(1980 ; 1999)$ identificaram que as experiências, resultantes do nosso aparato motor, perceptual e mental, são influenciadas pelas nossas relações com o ambiente físico e cultural. Isso significa que uma parte das propriedades que conceituam objetos ou fenômenos são inerentes a eles, mas outra parte é definida na relação com o entorno. E, uma vez que travamos contatos significativos com objetos e fenômenos novos no decorrer da vida - sendo alguns deles inusitados e difíceis de assimilar -, nossas formas de compreender e categorizar o mundo estão fundamentadas em experiências frequentes e, portanto, familiares.

Por exemplo, a relação entre o movimento em uma direção do espaço e a avaliação quantitativa de um atributo de medida, tal como a verticalidade, nos leva a associar, por conseguinte, o termo "mais" ao termo "para cima" na frase "os preços subiram". A variação quantitativa dos preços, que, a princípio, é um fenômeno abstrato, passa a ser entendida através da aproximação metafórica com uma experiência concreta a respeito da verticalidade. Sendo assim, "um julgamento subjetivo sobre quantidade é conceituado nos termos 
da experiência sensório-motora da verticalidade"(LAKOFF; JOHNSON, 1999). A correspondência entre quantidade e verticalidade surge das experiências do cotidiano e a correlação entre "mais" $e$ "para cima" se verifica em vivências, tais como empilhar livros sobre uma mesa.

A experiência da correlação "mais é para cima" leva ao estabelecimento de conexões entre "as redes neurais do cérebro que caracterizam 'mais' no domínio da quantidade e as redes que caracterizam 'para cima' no domínio da verticalidade" (LAKOFF; JOHNSON, 1999, p. 54). De acordo com a teoria das metáforas incorporadas, tais conexões mentais configurariam um mapa conceitual entre os termos "mais" e "para cima", tornando possível que qualquer palavra que possa ser utilizada para expressar verticalidade (por exemplo: crescimento, decréscimo, aumento, diminuição, altura, queda), venha a ser usada convencionalmente para indicar quantidade. Lakoff e Johnson (1999) relacionam a cognição a todo tipo de operação mental ou estrutura que pode ser estudada em termos precisos (GREINER, 2008). Deste modo, suas formulações a respeito da relação entre linguagem e ação permitem a descrição das associações metafóricas que formam um conceito, sob a forma de mapa conceitual.

A respeito disso, o exemplo de Lakoff (1979) sobre a metáfora do amor como uma jornada também serve de ilustração. $O$ autor constata que muitas expressões idiomáticas na língua inglesa se referem ao amor como um caminho a ser percorrido, uma viagem ou um meio para se chegar a algum lugar (e podemos pensar que a analogia também é válida para expressões idiomáticas existentes no português). As aproximações entre o amor e uma jornada constituem um conjunto de correspondências ontológicas que, por sua vez, caracterizam correspondências epistemológicas sobre os conhecimentos que temos acerca do amor (substantivo abstrato, subjetivamente apreendido), e sobre uma jornada (substantivo concreto, objetivamente apreendido). Tais correspondências permitem que pensemos sobre o amor usando os conhecimentos que temos para pensar sobre jornadas, e nos possibilitam buscar padrões de similaridade, bem como fazer inferências entre domínios distintos. 
Lakoff (1979) explica que a metáfora do amor como uma jornada é um mapa conceitual que caracteriza generalizações de dois tipos. (1) Polissêmicas: que envolvem generalizações de sentidos para expressões linguísticas usadas em referência ao domínio concreto, em relação ao domínio abstrato (por exemplo, quando dizemos que um relacionamento amoroso "não vai a lugar nenhum") e; (2) inferenciais: que envolvem generalizações inferências sobre a experiência do domínio abstrato, a partir da experiência do domínio concreto (por exemplo, a própria pressuposição de que o amor se assemelha, de alguma forma, a uma jornada). "A existência do mapa conceitual", diz o autor (LAKOFF, 1979, p. 209), "oferece uma resposta geral para as questões: 'por que as palavras que se referem a jornadas são usadas para descrever o amor?'e'por que os padrões de inferência usados para pensar sobre jornadas também são úteis para pensar sobre o amor"'. Para Lakoff (1979), assim como para Lakoff e Johnson (1980; 1999), a identificação de padrões polissêmicos e inferenciais nas metáforas "evidencia a existência dos mapas conceituais" (Lakoff, 1979, p. 209).

Contrariando a visão tradicional da teoria linguística, Lakoff e Johnson (1999) afirmam que as metáforas não resultam de processos conscientes de interpretação. As metáforas, nesse sentido, formam mapas conceituais imediatos, que se estabelecem por meio de conexões neurais, baseadas nas vivências do corpo. Em outras palavras, temos que a experiência sensório-motora está ligada a conexões neurais originárias de metáforas, e isso nos possibilita categorizar experiências, objetos e pessoas a partir daquilo que podemos apreender das interações diretas de nossos corpos com o ambiente. Assim, temos que "os mesmos mecanismos neurais e cognitivos que nos permitem perceber e mover são os que criam nossos sistemas conceituais e modos de razão" (GREINER, 2008, p. 45).

Para Lakoff e Johnson (1999), a razão é construída e se utiliza de formas de inferência perceptivas e motoras, que também estão presentes em outras espécies animais, conforme já havia sido pontuado por Bateson (1972). As metáforas, tais como os autores definem, fazem parte de uma "inconsciência cognitiva" (LAKOFF; JOHNSON, 1999, p. 56). Elas são adquiridas "automaticamente e inconscientemente via processo normal de aprendiza- 
gem neural" ((LAKOFF; JOHNSON, 1999, p. 56)) sobre o qual, em tese, não teríamos controle. Deste modo, os autores propõem que aquilo que chamamos de razão não é domínio exclusivo da consciência, porque algumas das metáforas que nos ajudam a compreender racionalmente o mundo são forjadas no domínio da inconsciência.

A ideia de que a significação compreende os esquemas da experiência corporal, proposta na teoria das metáforas incorporadas, também evidencia que nossa sensibilidade está assentada sobre estruturas pré-concebidas. Em outras palavras, os esquemas cognitivos, corporalmente inscritos não pertencem unicamente àqueles que têm a experiência, visto que fazem parte de um contexto cultural. Quando a comunidade onde estamos inseridos nos ajuda a determinar uma compreensão do mundo ao nosso redor, nos fornecendo subsídios para elaborar um entendimento incorporado das coisas do mundo por meio de metáforas, a existência que experimentamos se desenvolve no âmbito da cultura. Afinal, as metáforas conceituais se manifestam nos termos de construções culturais, tais como a linguagem, a gramática, os gestos, a arte e os rituais (LAKOFF; JOHNSON, 1980; 1999). Essa ideia vai ao encontro da proposta fenomenológica de Merleau-Ponty (2005) e do paradigma da corporeidade de Csordas (1990), segundo as quais as vivências pré-reflexivas não são anteriores à cultura.

\section{Discussão}

Aqui, fechamos o ciclo das teorias que nos propusemos a articular e relacionamos nossas reflexões à pesquisa sobre conhecimento prático, caracterizado como saber-fazer. Por meio da apresentação de teorias que esse artigo empreendeu, percebemos que a teoria das metáforas incorporadas de Lakoff e Johnson (1980; 1999) guarda relação com a perspectiva fenomenológica alinhada ao paradigma da corporeidade. De posse desses conhecimentos, temos subsídios para situar a percepção em uma rede com habilidade cognitiva que integre o corpo todo, e não apenas o cérebro e o sistema nervoso. Igualmente, podemos sustentar que a linguagem é um meio viável para acessar o sentido das experiências dos sujeitos no mundo, visto 
que as metáforas incorporadas nos permitem traçar os mapas conceituais da correlação entre as vivências do corpo e as palavras.

O objetivo deste artigo consistia em formular alternativas para transpor as dificuldades em se pesquisar o conhecimento prático a partir da perspectiva fenomenológica da corporeidade. Essas dificuldades estão orientadas em torno de pressupostos ontológicos da ciência moderna, quais sejam: os limites entre objetividade e subjetividade e as formas de representação e comunicação do conhecimento. A filiação ao paradigma da corporeidade implica uma orientação metodológica de acordo com a qual o corpo possa ser entendido como a base existencial da cultura (CSORDAS, 1990). As formas da episteme clássica, fundamentadas no conceito de representação, entendido a partir de uma organização binária entre "aquilo que é representado" e o"representante" (JAPIASSU, 1979, p. 120) sofreram mudanças quando da abertura para a fenomenologia na teoria antropológica, que possibilitou "articular um conceito de experiência em torno das bordas do paradigma monolítico textualista e representacionista" (CSORDAS, 2008, p. 368). Nessa nova paisagem intelectual, sujeito e objeto se unem em uma relação imbricada que não alcança, contudo, colapsar a tensão entre esses dois polos. A alteridade existe, mas não há, por parte do sujeito, o domínio de um sentido anterior ao sentido inculcado no objeto (VIVEIROS DE CASTRO, 2002).

Em outras palavras, o objeto não encerra uma estrutura inteligível que o sujeito possa desvendar, pois é o volver consciente do sujeito para o objeto que constitui a ambos, simultaneamente. Como observa Merleau-Ponty (2005, p. 59), "a atenção não é nem uma associação de imagens, nem o retorno a si de um pensamento já senhor de seus objetos, mas a constituição ativa de um objeto novo que explicita e tematiza aquilo que até então só se oferecera como horizonte indeterminado". Para Csordas (2008, p. 372), que problematizou sobre esta questão ao sugerir que a experiência dos nossos corpos e dos de outros devem ficar situadas nesse horizonte, o ato de constituição e o objeto que é constituído se encontram em um lugar existencialmente ambíguo definido como "horizonte fenomenológico".

Sendo assim, a condução de um estudo sob esta orientação epistemológica deve dedicar especial interesse aos modos somáticos de atenção, 
às maneiras culturalmente elaboradas de estar atento $a$ e com o corpo. A etnografia que é, em si, a prática definidora do tipo de esforço intelectual característico da Antropologia (GEERTZ, 1978), propicia também o engajamento sensório da pesquisadora ou do pesquisador no campo empírico e sugere que "prestar atenção ao corpo pode nos ensinar algo sobre o mundo e sobre os outros que nos rodeiam" (CSORDAS, 2008, p. 372). Nesse sentido, a transposição do método egresso da Antropologia para pesquisas em Educação parece ser apropriada para o estudo do conhecimento prático, ou para o modo de aprendizagem na prática que temos caracterizado aqui como saber-fazer. Assim, uma etnografia conduzida sob o paradigma da corporeidade deve tomar a "existência incorporada como ponto de partida para a análise da participação humana em um mundo cultural" (CSORDAS, 2008, p. 368). Isso sem que, ao contrário das práticas usuais da Ciência, tenhamos que enfatizar os comportamentos ou a fala em detrimento das experiências da percepção (MOREIRA, 2002).

A abordagem da corporeidade permite elaborar os modos somáticos de atenção como um constructo com algum valor empírico, mas também levanta a noção bastante escorregadia da indeterminação essencial da existência. Segundo Csordas (2008, p. 387), ela se coloca como problema quando"ao ter origem na experiência primordial caracterizada pela ausência da dualidade entre mente e corpo, eu e Outro, os fenômenos são objetificados em práticas reflexivas através de um modo somático de atenção específico". Esse retorno aos fenômenos, longe de lhes dar uma explicação causal, implica dificuldades em encontrar categorias descritivas necessárias à transcrição dos mesmos. Assim, "o que é revelado por um retorno aos fenômenos - e a consequente necessidade de colapsar dualidades de mente e corpo, eu e Outro - é em vez disso um princípio fundamental de indeterminação que apresenta um profundo desafio metodológico ao ideal científico" (CSORDAS, 2008, p. 387). Para Geertz (1978), que se filia ao paradigma semiótico da cultura como texto, este é um problema mais literário do que existencial: afinal, para resolvê-lo, bastaria transcrever a experiência que se revela no pesquisador para dar vazão àqueles fragmentos de vivência incompreensíveis, porém significativos. Para Csordas (2008, p. 389), porém, esta não é uma questão de linguagem, mas 
sim de se tomar a indeterminação existencial como "base para a transposição de diferentes esquemas em diferentes domínios práticos".

Todavia, há que se levar em conta que a indeterminação fundamental ao paradigma da corporeidade deve ser cuidadosamente elaborada, em termos teórico-práticos, de modo que não se torne pretexto para imprecisão analítica. Por isso, é recomendável que a pesquisa etnográfica se desenvolva segundo modelos fenomenológicos, tais como as categorias da etnografia da experiência, enunciada por Kleinman e Kleinman (1991), ou os preceitos da conversão moral e sensual como técnica de observação e análise, descrita por Wacquant (2002, p. 11, grifo no original). Ambas as abordagens metodológicas tomadas aqui como referência, trazem implícitas a condição de serem teoricamente instrumentadas sem, contudo, deixarem de permitir à pesquisadora ou ao pesquisador apropriar-se na e pela prática das formas intersubjetivas de memória e ação. Ambas também posicionam a pesquisadora ou o pesquisador no campo como alguém que pode compartilhar do ponto de vista nativo quando entende o que as práticas engendradas na vida cotidiana significam e o que está em jogo através delas. Esses dois estudos tomam o corpo como o ponto de partida metodológico em vez de objeto de estudo.

BETWEEN LANGUAGE AND KNOW-HOW: A PROPOSAL FOR THE UNDERSTANDING OF PRACTICAL KNOWLEDGE

ABSTRACT: The paper aims to formulate alternatives to cross the difficulties of studying the phenomenon of learning through practice, which is known as know-how. For this purpose, we have built theoretical articulations that put side by side a phenomenological perspective, based on the embodiment paradigm, and an approach that gathers language and practice, which is the theory of embodied metaphors. We understand that such difficulties are oriented around ontological premises of the modern science, which are: the limits between objectivity and subjectivity and representational ways of communicating knowledge. We conclude that ethnographical research conducted according to phenomenological models, such as the categories of ethnography of experience, is a proper methodological alternative for studying practical knowledge.

KEYWORDS: Practical knowledge. Embodiment paradigm. Know-how. Ethnography. 
ENTRE EL LENGUAJE Y EL SABER-HACER: UNA PROPUESTA PARA LA COMPRENSIÓN DEL CONOCIMIENTO PRÁCTICO

RESUMEN: El artículo tiene como objetivo formular alternativas para superar las dificultades en la investigación del fenómeno de aprendizaje en la práctica, entendida como saber-hacer. Para ello, construimos articulaciones teóricas que ponen en paralelo una perspectiva fenomenológica, basada en el paradigma de la corporeidad, y un abordaje que reúne lenguaje y práctica, en la teoría de las metáforas corporificadas. Se entiende que tales dificultades se orientan en torno de presupuestos ontológicos de la ciencia moderna, a saber: los límites entre la objetividad y la subjetividad y las formas de representación y comunicación del conocimiento. Concluimos que la investigación etnográfica realizada segundo modelos fenomenológicos, tales como las categorías de la etnografía de la experiencia, sea una propuesta metodológica adecuada para el estudio del conocimiento práctico.

Palabras clave: Conocimento practico. Paradigma de la corporeidad. Saber-hacer. Etnografía.

\section{REFERÊNCIAS}

BATESON, G. Steps to an ecology of mind: Collected essays in Anthropology, Psychiatry, Evolution and Epistemology. São Francisco, Scranton, Londres e Toronto: Chandler, 1972.

CARVALHO, I.C; STEIL, C.A. A sacralização da natureza e a 'naturalização' do sagrado: aportes teóricos para a compreensão dos entrecruzamentos entre saúde, ecologia e espiritualidade. Ambiente e Sociedade, Campinas, v. 11, n. 2, p. 289-305, 2008.

CSORDAS, T. Embodiment as a paradigm to Anthropology. Ethos, v. 18, n. 1, p. 5-47, 1990.

Corpo, significado, cura. Porto Alegre: UFRGS, 2008.

FURLAN, R.; BOCCHI, J. C. Corpo como expressão e linguagem em Merleaul-Ponty. Estudos de Psicologia, v. 3, n. 1, p. 445-450, 2008.

GEERTZ, C. A Interpretação das Culturas. Rio de Janeiro: Zahar Editores, 1978.

GREINER, C. O corpo: pistas para estudos indisciplinares. São Paulo: Annablume, 2008. HUTCHINS, E. Cognition in the wild. Cambridge: MIT Press, 1995.

JAPIASSU, H. Introdução ao pensamento epistemológico. Rio de Janeiro: Francisco Alves, 1979.

LAKOFF, G. The contemporary theory of metaphor. In: ORTONY, A. (Org.) Metaphor and thought. Cambridge: Cambridge University Press, 1979. 
LAKOFF, G.; JOHNSON, M. Metaphors we live by. Chicago: University of Chicago Press, 1980.

Philosophy in the flesh: the embodied mind and its challenge to Western thought. New York: Basic Books, 1999.

KLEINMAN, A.; KLEINMAN, J. Suffering and its professional transformation: toward an ethnography of experience. Culture, Medicine and Psychiatry, n. 15, p. 275-302, 1991.

MERELAU-PONTY, M. Fenomenologia da percepção. São Paulo: Martins Fontes, 2005.

MOREIRA, D. A. O método fenomenológico na pesquisa. São Paulo: Thompson Pionei$\mathrm{ra}, 2002$.

PIAGET, J. Six psychological studies. New York: Vintage, 1967.

REDDY, M. The conduit metaphor. In: ORTONY, A. (Org.) Metaphor and thought. Cambridge: Cambridge University Press, 1979.

VARELA, F. Neurophenomenology: a methodological remedy for the hard problem. Journal of consciousness studies, v. 3, n. 4, p. 330-349, 1996.

VELHO, O. De Bateson a Ingold: passos na constituição de um paradigma ecológico. Mana, v. 7, n. 2, p. 133-140, 2001.

VIVEIROS DE CASTRO, E. Os pronomes cosmológicos e o perspectivismo ameríndio. Mana, v. 2, n. 2, p. 115-144, 1996.

WACQUANT, L. Corpo e alma: notas etnográficas de um aprendiz de boxe. Rio de Janeiro: Relume Dumará, 2002.

MARINA DANTAS DE FIGUEIREDO: Doutora em Administração pela Universidade Federal do Rio Grande do Sul (UFRGS). Professora Adjunta da Universidade de Fortaleza (Unifor). Atualmente, seus interesses de pesquisa estão votados para os estudos sobre: Estudos Organizacionais - Cultura Organizacional, Estudos sobre Cultura e Práticas Organizacionais/Gestão de Pessoas: Aprendizagem e Conhecimento Organizacional, Gestão e Subjetividade, Estudos sobre Gênero e Relações de Trabalho.

E-mail: marina.dantas@unifor.br 